\title{
Daytime sleep in myotonic dystrophy is not caused by sleep apnoea
}

\author{
F G A van der Meché, J M Bogaard, J C $M$ van der Sluys, R J Schimsheimer, \\ C C M Ververs, H F M Busch
}

\begin{abstract}
Daytime sleepiness is common in myotonic dystrophy and might be attributed to disturbed nocturnal breathing. Seventeen out of 22 patients complained of excessive daytime sleepiness, resembling "idiopathic hypersomnolence". Sleep apnoea might have contributed to daytime sleepiness in only three of 17 patients. Treatment with the central stimulant methylphenidate produced sustained benefit in seven out of 11 patients tested. Daytime sleepiness in myotonic dystrophy is usually caused by dysfunction of central sleep regulation and not by disturbed nocturnal breathing.
\end{abstract}

(F Neurol Neurosurg Psychiatry 1994;57:626-628)

Myotonic dystrophy is the most frequent form of muscular dystrophy. It is not only a muscle disease but a multiorgan disorder, and one of the organs affected is the nervous system. ${ }^{1}$ Complaints about excessive sleepiness are well known in these patients. This has been attributed to sleep apnoea or to respiratory insufficiency. ${ }^{1}$ After an extensive case study, we suggested that severe sleepiness in myotonic dystrophy might be caused by a dysfunction of the CNS. ${ }^{2}$ This is important as centrally caused sleepiness can usually be treated with central stimulants. The present study was undertaken to study the incidence and clinical picture of hypersomnolence and the relation with nocturnal breathing abnormalities.

\section{Departme}

F G A van der Mech

J C M van der Sluys

R J Schimsheimer

C C M Ververs

H F M Busch

Department of

Pulmonary Diseases,

University Hospital

Rotterdam - Dijkzigt

The Netherlands

J M Bogaard

Correspondence to:

Professor Dr F G A van der Meché, Department of Neurology, University Hospital Rotterdam Dijkzigt, Dr Molewaterplein 40, 3015 GD Rotterdam, The Netherlands.

Received 17 June 1991 and in final revised form

9 February 1993.

Accepted 25 March 1993

\section{Patients and methods}

Twenty two consecutive patients were studied, 14 men (median age 36; range 16-57) and eight women (median age 50; range 23-67). Diagnosis of myotonic dystrophy was based on the presence of myotonia, the typical distribution of muscle weakness, and an a priori risk of $50 \%$ for myotonic dystrophy from the family history. One patient was confined to a wheelchair; all others were ambulant and independent as far as day to day activities were concerned. Reasons for referral were hypersomnolence (11), weakness (3), respiratory problems (3), ileus (1), and pre- operative screening (4). Patients were not obese (median body weight for men, 67 (range 48-91) kg; for women, 62 (range 45-80) kg). Cardiovascular state was stable in all and no medication was given during the evaluations.

A standard questionnaire was used to evaluate complaints about sleepiness or breathing and to obtain information on sleeping habits. Nocturnal breathing was studied in the initial five patients by inductive plethysmography (Respitrace), and in the 17 other patients by polysomnography including EEG, electrooculogram, chin electromyography, airflow measured with thermistors in front of the nose and mouth, chest and abdominal movement, diaphragm EMG measured externally, ${ }^{3}$ ECG, and transcutaneous oxygen saturation. Sleep stages were divided into light sleep and deep sleep, stages I and II and stages III and IV respectively according to Rechtschaffen and Kales, ${ }^{4}$, and REM-sleep.

Periodic breathing was defined as gradual crescendo-decrescendo fluctuations of one third or more of the flow and breathing movements (see figure for example). This was scored for four minute epochs in which at least two such periods had to be present for a positive score. Apnoea was defined as absence of air flow for at least 10 seconds. In central apnoeas, breathing movements were also absent; obstructive apnoeas were defined as absence of air flow with thoracal and abdominal movements in counterphase.

The sleep analysis was compared with data from 10 neurologically healthy controls, median age 38 , range $17-59$, who were recorded under identical conditions.

The effect of methylphenidate was evaluated in 11 patients in open trials.

\section{Results}

SLEEPINESS

Eleven patients were referred for daytime sleepiness; from the other 11 referred for other reasons, six complained about severe sleepiness. Five did not complain but three of them had less pronounced similar daytime and nocturnal sleeping habits as did the group of 17 complaining patients. A characteristic clinical picture emerged from the standard questionnaires of these 17 patients: they were long, quiet sleepers difficult to 


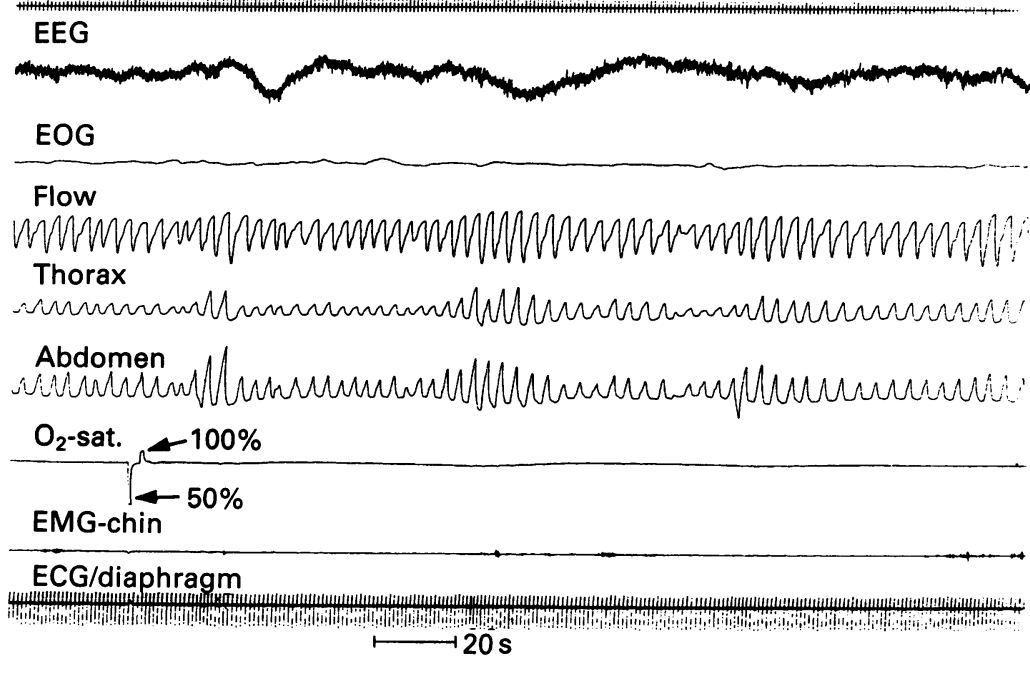

Figure Periodic breathing during light sleep; the flow and the movements of thorax and abdomen show phases with increasing and decreasing amplitudes. Oxygen saturation varies only slightly. Percentages give the values of the calibration phase of the oxygen saturation channel. emerge (15 out of 22 patients). Obstruction of the upper airway only occurred in a minority (5 out of 15 apnoeic patients), however, when breathing movements resumed, resulting in mixed central-obstructive apnoeas (table). Only minor fluctuation in oxygen saturation occurred in parallel, usually within a range of $5 \%$ of the baseline value. The lowest saturation in all recordings was $80 \%$ in one not sleepy patient during a single apnoea period.

Five patients fulfilled the criteria for sleepapnoea-namely, more than five apnoeas per hour of sleep. All five showed central apnoeas and two of them were in the not sleepy group (table). These breathing abnormalities did not seem to influence the general sleep structure and they always disappeared in deep sleep.

\section{TREATMENT}

Eleven sleepy patients were given methylphenidate. Starting with a dose of 10 $\mathrm{mg}$ daily, this was increased to $10-20 \mathrm{mg}$ twice daily. Seven out of 11 patients showed a persisting positive effect at follow up two to six years later. After treatment with the drug, sleepiness was suppressed for three to five hours. In two patients the beneficial effect lasted only a few weeks before tolerance developed with doses of $40 \mathrm{mg} /$ day. Therefore the drug was discontinued. In one further patient a beneficial effect occurred, but the drug had to be discontinued because of intolerable feelings of personality change. No effect was found in one patient. 17 patients did not feel refreshed after a nap.

Onset of complaints was variable, from childhood in six patients up to a maximum age of onset of 60 years. No relation could be found with muscle weakness. In some of the patients this was retrospectively the first complaint of the disease. In one patient, a man of 45 years referred for hypersomnolence, other symptoms of the disease were only slight and had not been previously discovered. Finally, the patient, who was confined to a wheelchair did not complain about sleepiness, slept only 6.5 hours a night, and was refreshed in the morning.

During polysomnography in the hospital, the median duration of sleep in the patients was 7.9 (range 5.3 to 10.9 ) hours. For the control group the values were lower (median 6.05 (range 3.3 to 8.0 ) hours; $\mathrm{p}=0.003$ ). Deep sleep (median, range) occurred in patients during $29 \%(16 \%-39 \%)$; in controls during $11.5 \%(0 \%-23 \% ; p=0.0001)$ of the recording. REM-sleep occurred during $12 \%$ $(0 \%-30 \%)$ in patients and during $19 \%$, $(5 \%-21 \% ; p=0.3)$ in controls. A normal succession of sleep stages was the rule in most patients; only sporadic awakenings or arousals occurred.

\section{NOCTURNAL BREATHING}

Twenty out of 22 patients showed periodic breathing (figure, table). This was not related to sleepiness during the day or to the presence of snoring at night (table). In many patients, the fluctuations in tidal volume were so large at times that central apnoeas could

\section{Discussion}

Hypersomnolence in myotonic dystrophy is a well known complaint. ${ }^{5}$ In our study, 11 patients were referred for this reason and in the other 11, six also complained of excessive sleepiness. The typical pattern was long, quiet nocturnal sleep with great difficulty waking up in the morning; both sleep duration and percentage of deep sleep were significantly longer compared with controls. During daytime the feeling of sleepiness persisted without relief from long naps. This pattern is compatible with the syndrome, "idiopathic hypersomnolence", which might be considered as an extreme of normal sleep regulation and which can be treated with central stimulants. ${ }^{5}$

Daytime sleepiness could not be attributed to abnormalities of nocturnal breathing in our patient group. Only three of the 17 sleepy patients had more than five apnoeas an hour,

Table Relation between nocturnal breathing and daytime sleepiness in 22 patients with myotonic dystrophy

\begin{tabular}{lll}
\hline & Sleepy $(n=17)$ & Not sleepy $(n=5)$ \\
\hline Snoring (n) & 7 & 2 \\
Periodic breathing (n) & 15 & 5 \\
Apnoeas (n) & 11 & 4 \\
Central (n) & 7 & 3 \\
Mixed (n) & 4 & 1 \\
Apnoeas/h (range) & $1-9$ & $1-11$ \\
$>5$ apnoeas/h (n) & 3 & 2 \\
\hline
\end{tabular}


whereas two out of five non-sleepy patients also had a sleep-apnoea syndrome based on this criterion; all had central apnoeas. Five apnoeas an hour, although this is the threshold of the sleep-apnoea syndrome, usually do not cause hypersomnolence. Some neurologically healthy snorers, however, may be sleepy without regular apnoeas, presumably due to increased airway resistance and sleep fragmentation. ${ }^{6}$ In our group, however, obstruction was not primarily involved as most apnoeas were of the central type and no apnoea started with an obstruction. Central apnoeas cause less oxygen desaturation and sleep disturbance than obstructive sleep apnoeas and therefore rarely hypersomnolence. ${ }^{5}$

Our findings on breathing are in agreement with these of Cirignotta et $a l_{,}^{7}$ who also found slight apnoea, predominantly of a central origin in six patients. Cummiskey et al, ${ }^{8}$ however, described more severe obstructive apnoea that might explain sleepiness in some of their patients. Differences in referral patterns between a neurological clinic and a sleep centre might well explain the difference in incidence of the more severe apnoea syndromes.

Progressive weakness leading to chronic alveolar hypoventilation at night might also result in sleepiness during the day. ${ }^{9}$

Prolonged periods of oxygen desaturation associated with significant alveolar hypoventilation was, however, not found in our patients. Recently we were able to prove in a patient, admitted for respiratory insufficiency, that even in such circumstances sleepiness might well originate in the CNS. In this patient sleepiness was successfully treated with central stimulants. ${ }^{2}$
Although hypersomnolence in most patients is central in origin, it would seem prudent to perform polysomnographic studies in patients who are predisposed for the obstructive sleep-apnoea syndrome by snoring or obesitas, or who have considerable weakness of respiratory muscles. If uncertainty exsists about the contribution of apnoeas to hypersomnolence, a trial with nasal continuous positive airway pressure suppressing the apnoeas may solve the dilemma. If the hypersomnolence is of central origin, treatment with a central stimulant might be worthwhile, as seven out of 11 patients treated in this study with low doses of methylphenidate reported sustained benefit for several years.

CCMV was supported by Het Prinses Beatrix Fonds No 88-2895). We further acknowledge L Penning de Vries, neurologist, for her cooperation in the initial stage of the study, and Ms $R$ M van den Hoven for excellent secretarial support.

1 Harper PS. Myotonic dystrophy. Philadelphia: WB Saunders, 1979.

2 Van der Meché FGA, Bogaard JM, Berg $B$ van den. Treatment of hypersomnolence in myotonic dystrophy with a CNS stimulant. Muscle Nerve 1986;9:341-4.

3 Newsom Davis J. Phrenic nerve conduction in man. $f$ Neurol Neurosurg Psychiatry 1967;30:420.

4 Rechtschaffen A, Kales A. A manual of standardized terminology, techniques and scoring system for sleep stages of human subjects. Los Angeles: Brain Information Service, Brain Research Institute, University of California, 1968.

5 Parkes JD. Sleep and its disorders. Philadelphia: WB Saunders, 1985.

6 Guilleminault C, Stoohs R, Duncan S. Daytime sleepiness in regular heavy snorers. Chest 1991;99:40-8.

7 Cirignotta F, Mondini S, Zucconi M, et al. Sleep-related breathing impairment in myotonic dystrophy. $\mathcal{F}$ Neurol breathing impai

8 Cummiskey J, Lynne-Davies P, Guilleminault C. Sleep study and respiratory function in myotonic dystrophy. In: Guilleminault C, Dement WC, eds. Sleep apnoea syndrome, New York: Alan R Liss, 1978:295-308.

9 Kilburn KH, Eagan JT, Sieker HO, Heyman A. Cardiopulmonary insufficiency in myotonic and progressive muscular dystrophy. N Engl f Med 1959;261:1089-96. 